\title{
Factors related to choice of modern $v$ s traditional contraceptives among women in rural Sri Lanka
}

\author{
Janitha Hettiarachchi ${ }^{1}$, Nalika S Gunawardena ${ }^{2}$ \\ Sri Lanka Journal of Obstetrics and Gynaecology 2011; 33: 20-25
}

\begin{abstract}
Objectives: Sri Lankan family planning progrmme aims to promote modern contraceptives. This study was aimed to assess factors associated with choice of traditional versus modern contraceptives among women in a rural setting in Sri Lanka
\end{abstract}

Methods: Two groups of traditional method $(n=217)$ and modern method $(n=217)$ users were studied using an interviewer-administered questionnaire.

Results: Age >35 years $(\mathrm{p}<0.001)$, Muslim ethnicity $(p=0.045)$, living with extended families $(p<0.001)$, not having children $(p<0.001)$, youngest child being $>6$ years $(p=0.012)$, non-receipt of detailed information on modern methods $(\mathrm{p}<0.001)$, public health midwife $(\mathrm{PHM})$ not visiting homes $(\mathrm{p}<0.001)$, living $>1 \mathrm{~km}$ from field clinic $(\mathrm{p}=0.002)$, nonutilization of field clinic services $(p<0.001)$, negative opinions about $\mathrm{PHM}$ 's services $(p<0.001)$, negative opinion regarding services at field clinic $(\mathrm{p}<0.001)$ and poor knowledge on modern contraceptives $(p=0.015)$ were associated with the choice of traditional methods.

Conclusions: Choice of traditional method was associated with personal factors as well as service gaps.

Key words: traditional contraceptives, rural Sri Lanka, modern contraceptives.

\section{Introduction}

Use of contraceptives facilitates planning of families. Contraceptive methods are broadly categorized into two main groups as modern and

\footnotetext{
${ }^{1}$ Postgraduate Institute of Medicine, University of Colombo.

${ }^{2}$ Faculty of Medicine, University of Colombo. Correspondence: Nalika Gunawardena

E-mail:nalikaguna@hotmail.com
}

traditional. In general, traditional methods have a markedly high failure rate compared to the modern methods. Use of contraceptive methods with high failure rate may lead to unplanned pregnancies.

Thirteen percent of all maternal deaths globally have been found to be due to illegal abortions performed to get rid of unplanned pregnancies and these deaths are seen more in developing countries ${ }^{1}$. Unplanned pregnancies can also affect the woman in other ways. They are less likely to seek care than a woman who has planned her pregnancy resulting in undetected maternal complications ${ }^{2}$. Psychological distress associated with unplanned pregnancy makes them more prone to postpartum psychosis ${ }^{3}$. As unplanned pregnancies are usually closely spaced with a previous pregnancy, it results in deterioration of mother's health. Unplanned pregnancy could affect child's life also in several ways ${ }^{4}$.

Sri Lanka is a developing country situated in the southeast Asian region with health indices almost similar to developed countries. Family planning services in the state sector is well established and contraceptives are provided to clients free of charge ${ }^{5}$. The state aims to promote modern contraceptive methods. Oral contraceptive pills, Depo Medroxy Progesterone Acetate injection (DMPA), intrauterine devices, hormonal implants, female and male condoms and male and female sterilization are the modern methods practiced in Sri Lanka ${ }^{6}$. Induced abortions are illegal in the country. Coitus interruption and periodic abstinence from intercourse are the main traditional methods used by couples in the country ${ }^{6}$.

The country's decentralized field health system delivers contraceptives to clients. A Medical Officer of Health $(\mathrm{MOH})$ area is the smallest level in field health system. There are $280 \mathrm{MOH}$ areas, in the country at present ${ }^{5}$. Field health services are delivered by a team of health workers and public health midwives (PHM) are the grass root level health workers delivering family planning services. A single PHM is responsible to provide services for a population of 3000-5000 residents. PHM pays home visits to eligible families distributing oral contraceptive pills and condoms. Intrauterine devices, hormonal implants and DMPA are provided through field clinics conducted within the $\mathrm{MOH}$ area. Clients are referred to curative health institutions with surgery and gynaecology services for male and female surgical sterilizations ${ }^{7}$. 
Though, the family planning service delivery network in Sri Lanka is cited as one of the best in the south Asian region, among the regional countries Sri Lanka is estimated as one of the countries with high proportions $(15-21 \%)$ of who rely on traditional methods $^{8}$

The Demographic and Health Surveys (SLDHS) in 2006/2007 revealed that out of 15068 married women $70.2 \%$ used contraceptives with 17\% practicing traditional methods and $53.1 \%$ using modern methods. Among users, the proportion of traditional method users was $24.2 \%{ }^{6}$. There is also evidence that maternal deaths as a complication of illegal abortion to get rid of unplanned pregnancies are a problem in Sri Lanka9. Of the maternal deaths in $2005,39 \%$ were due to unplanned pergnancies ${ }^{10,11}$ Septic abortions has been placed as the fourth leading cause for maternal deaths in $2005^{11}$. De Silva (1996) estimated that in Sri Lanka, the number of illegal abortions to be $125,000-175,000$ each year and that seven illegal abortions take place for every 10 births $^{12}$. Rural women were the majority among those who sought illegal abortions.

Despite high use of traditional contraceptives with high failure rates and evidence of adverse consequences of resultant unplanned pregnancies, factors associated with choice of traditional methods have not been studied in Sri Lanka. It is imperative that such factors need to be addressed by targeted interventions, encouraging the traditional method users to take up modern methods. The present study aimed to compare factors associated with choice of traditional and modern family planning methods among women in a rural setting in Sri Lanka.

\section{Materials and methods}

We conducted a community based comparative cross-sectional study among traditional and modern contraceptive users in Haliela $\mathrm{MOH}$ area which is a rural setting in the Badulla district in Uva province.

We calculated the sample size which was 217 per group, based on estimates of education level of women using traditional methods and modern methods $s^{6,13}$. We defined a traditional user as a married woman in reproductive age who was using only a traditional method at the time of the study while a modern contraceptive user was defined as a married woman in reproductive age who was using only a modern method at the time of study. We utilized cluster sampling technique and considered rural public health midwife area or an estate as a cluster. We conducted the study in 12 clusters. In keeping with the proportion of 28 rural public health midwives areas and 12 estate public health midwives areas, we randomly selected 8 rural area clusters and 4 estate clusters to be included in the study. Eligible study units were selected by a household survey. Upon informed verbal consent, trained interviewers (first author and two other medical officers) administered pre-tested questionnaire in local language. We collected data during August 2009. Ethical clearance was obtained from the Ethics Review Committee of the Faculty of Medicine, University of Kelaniya. Statistical analysis was performed using Statistical Package for Social Sciences (SPSS) version 12.0.

\section{Results}

The overall response rate was 98.2\% (426/434). The response rate among modern method users and traditional method users were 97.6\% (212/217) and $98.6 \%(214 / 217)$, respectively.

Comparison of socio-demographic characteristics of traditional and modern contraceptive users are shown in Table 1. A significantly higher proportion of those aged 35 years and above $(p<0.001)$, Muslim nationality $(p=0.045)$, living in an extended family $(p=0.001)$ were using traditional methods.

Comparison of traditional and modern contraceptive users by reproductive health related factors are shown in Table 2 . Women with no children at the time of survey $(p=0.001)$ and whose youngest child's age was $>6$ years $(p=0.012)$ had chosen traditional family planning methods over modern methods.

A significantly higher proportion of women who had not received detailed information regarding modern methods $(p=0.011)$, who have never been visited at homes by the PHM $(\mathrm{p}<0.001)$, who had negative opinion about services of PHM $(p<0.001)$, whose residences were $>1 \mathrm{~km}$ from the field clinic $(p=0.002)$, who had never utilized field clinic services $(p<0.001)$, those with negative opinion about services at field clinic $(p<0.001)$ were in favour of traditional methods than modern methods (Table 3).

We assessed knowledge of modern methods based on a score (range of marks maximum - 23 minimum - 0) obtained for a set of questions. We categorized women into three levels of knowledge (Good - > 18 marks, Average - 13 to 17 marks, Poor $<13$ marks) based on their average scores (Table 4). A higher percentage of traditional method users (30.4\%) had poor knowledge on modern methods compared to modern method users $(18.9 \%)(p=0.015)$. 
Table 1. Comparison of frequency distributions of traditional and modern contraceptive users by the socio-demographic characteristics

\begin{tabular}{|c|c|c|c|c|c|}
\hline \multirow[t]{2}{*}{ Characteristic } & \multicolumn{2}{|c|}{ Modern methods } & \multicolumn{2}{|c|}{ Traditional methods } & \multirow[t]{2}{*}{ Significance } \\
\hline & No. & $\%$ & No. & $\%$ & \\
\hline \multicolumn{6}{|l|}{ Woman's age } \\
\hline$<35$ years & 153 & 72.2 & 119 & 55.6 & $X^{2}=15.582$ \\
\hline$>35$ years & 59 & 27.8 & 95 & 44.4 & $\mathrm{df}=1, \mathrm{p}<0.001$ \\
\hline \multicolumn{6}{|l|}{ Occupation } \\
\hline House wife & 145 & 68.4 & 132 & 61.7 & $X^{2}=2.111$ \\
\hline Others occupations & 67 & 31.6 & 82 & 38.3 & $\mathrm{df}=1, \mathrm{p}=0.146$ \\
\hline \multicolumn{6}{|l|}{ Nationality } \\
\hline Muslims & 20 & 9.4 & 34 & 15.9 & $X^{2}=4.007$ \\
\hline Others & 192 & 90.6 & 180 & 84.1 & $\mathrm{df}=1, \mathrm{p}=0.045$ \\
\hline \multicolumn{6}{|l|}{ Education level } \\
\hline Up to G.C.E. O/L & 141 & 66.5 & 124 & 57.9 & $X^{2}=3.323$ \\
\hline G.C.E. O/L and above & 71 & 33.5 & 90 & 42.1 & $\mathrm{df}=1, \mathrm{p}=0.068$ \\
\hline \multicolumn{6}{|l|}{ Family type } \\
\hline Nuclear family & 126 & 59.4 & 92 & 43.0 & $X^{2}=11.524$ \\
\hline Extended family & 86 & 40.6 & 122 & 57.0 & $\mathrm{df}=1, \mathrm{p}=0.001$ \\
\hline \multicolumn{6}{|l|}{ Monthly income } \\
\hline < Rs.10000 (USD 100) & 93 & 43.9 & 102 & 47.7 & $X^{2}=0.618$ \\
\hline > Rs. 10000 (USD 100) & 119 & 56.1 & 112 & 52.3 & $\mathrm{df}=1, \mathrm{p}=0.432$ \\
\hline
\end{tabular}

Table 2. Comparison of frequency distributions of traditional and modern contraceptive users by reproductive health related factors

\begin{tabular}{|c|c|c|c|c|c|}
\hline \multirow[t]{2}{*}{ Reproductive health related factors } & \multicolumn{2}{|c|}{ Modern methods } & \multicolumn{2}{|c|}{ Traditional methods } & \multirow[t]{2}{*}{ Significance } \\
\hline & No. & $\%$ & No. & $\%$ & \\
\hline \multicolumn{6}{|l|}{ Woman's age at marriage } \\
\hline$<27$ yrs & 12 & 5.7 & 20 & 9.3 & $X^{2}=2.082$ \\
\hline$>27$ years & 200 & 94.3 & 194 & 90.7 & $\mathrm{df}=1, \mathrm{p}=0.149$ \\
\hline \multicolumn{6}{|c|}{ Having children at the time of survey } \\
\hline yes & 209 & 98.6 & 182 & 85.0 & $X^{2}=25.884$ \\
\hline No & 3 & 1.4 & 32 & 15.0 & $\mathrm{df}=1, \mathrm{p}=0.001$ \\
\hline \multicolumn{6}{|c|}{ Number of children at the time of survey among those who were having children } \\
\hline 1 to 2 children & 138 & 66.0 & 122 & 67.0 & $X^{2}=4.420$ \\
\hline 3 to 4 children & 64 & 30.7 & 46 & 25.3 & $\mathrm{df}=2, \mathrm{p}=0.110$ \\
\hline$>4$ children & 7 & 3.3 & 14 & 7.7 & \\
\hline \multicolumn{6}{|c|}{ Age at 1st child birth among those who were having children } \\
\hline$<25$ years & 140 & 67.0 & 110 & 60.4 & $X^{2}=1.997$ \\
\hline $25 y r s$ and above & 69 & 33.0 & 72 & 39.6 & $\mathrm{df}=1, \mathrm{p}=0.154$ \\
\hline \multicolumn{6}{|c|}{ Youngest child's age survey among those who were having children } \\
\hline 0 to 6 years & 172 & 82.3 & 131 & 72.0 & $X^{2}=6.380$ \\
\hline$>6$ years & 37 & 17.7 & 51 & 28.0 & $\mathrm{df}=1, \mathrm{p}=0.012$ \\
\hline
\end{tabular}


Table 3. Comparison of frequency distributions of traditional and modern contraceptive users by service related factors associated with contraceptive use

\begin{tabular}{|c|c|c|c|c|c|}
\hline \multirow[t]{2}{*}{ Service related factor } & \multicolumn{2}{|c|}{ Modern methods } & \multicolumn{2}{|c|}{ Traditional methods } & \multirow[t]{2}{*}{ Significance } \\
\hline & No. & $\%$ & No. & $\%$ & \\
\hline \multicolumn{6}{|c|}{ Ever received detailed information regarding modern family planning } \\
\hline Yes & 158 & 74.5 & 135 & 63.1 & $X^{2}=6.495$ \\
\hline No & 54 & 25.5 & 79 & 36.9 & $\mathrm{df}=1, \mathrm{p}=0.011$ \\
\hline \multicolumn{6}{|l|}{ Ever met area PHM } \\
\hline Yes & 201 & 94.8 & 200 & 94.4 & $X^{2}=0.353$ \\
\hline No & 11 & 5.2 & 14 & 5.6 & $\mathrm{df}=1, \mathrm{p}=0.552$ \\
\hline \multicolumn{6}{|c|}{ PHM ever visited home } \\
\hline Yes & 192 & 95.5 & 160 & 80.0 & $X^{2}=22.519$ \\
\hline No & 9 & 4.5 & 40 & 20.0 & $\mathrm{df}=1, \mathrm{p}<0.001$ \\
\hline \multicolumn{6}{|c|}{ Opinion about services of PHM } \\
\hline Positive & 160 & 81.6 & 112 & 62.6 & $X^{2}=17.065$ \\
\hline Negative & 36 & 18.4 & 67 & 37.4 & $\mathrm{df}=1, \mathrm{p}<0.001$ \\
\hline \multicolumn{6}{|c|}{ Distance to the field family planning clinic } \\
\hline$<1 \mathrm{~km}$ & 96 & 45.3 & 66 & 30.8 & $X^{2}=9.425$ \\
\hline $1 \mathrm{~km}$ or $>$ & 116 & 54.7 & 148 & 69.2 & $\mathrm{df}=1, \mathrm{p}=0.002$ \\
\hline \multicolumn{6}{|c|}{ Ever utilized the field family planning clinic } \\
\hline Yes & 206 & 97.2 & 186 & 86.9 & $X^{2}=15.247$ \\
\hline No & 6 & 2.8 & 28 & 13.1 & $\mathrm{df}=1, \mathrm{p}<0.001$ \\
\hline \multicolumn{6}{|c|}{ Opinion regarding field family planning clinic } \\
\hline Positive & 166 & 80.6 & 112 & 64.4 & $X^{2}=12.629$ \\
\hline Negative & 40 & 19.4 & 62 & 35.6 & $\mathrm{df}=1, \mathrm{p}<0.001$ \\
\hline
\end{tabular}

Table 4. Comparison of frequency distributions of traditional and modern contraceptive users by overall knowledge on modern family planning

\begin{tabular}{lccccc}
\hline $\begin{array}{l}\text { Overall knowledge on } \\
\text { modern family planning }\end{array}$ & \multicolumn{2}{c}{ Modern methods } & Traditional methods & Significance \\
\cline { 2 - 5 } & No. & $\%$ & No. & $\%$ \\
\hline Good & 67 & 31.6 & 51 & 23.8 & $X^{2}=8.354$ \\
Average & 105 & 49.5 & 98 & 45.8 & $\mathrm{df}=2, \mathrm{p}=0.015$ \\
\hline
\end{tabular}




\section{Discussion}

In the present study we found that significantly higher proportion of women over 35 years preferred traditional methods $(p<0.001)$. The fact that higher proportion of women in late reproductive age and have chosen less effective traditional methods is a concern as failure of the method may lead to elderly pregnancies which are associated with many medical and social problems. A research in Bangladesh in 1986 also confirmed that more women in late reproductive years were using traditional methods ${ }^{14}$. However, a review of qualitative research on choice of family planning methods indicated opposite findings. It reported that young women often relied on traditional methods or abortion rather than modern methods ${ }^{15}$.

Our study showed that women of Muslim nationality $(p=0.045)$ were relying more on traditional methods. The reason may be related to the religion. This was expressed by Rogow for withdrawal method being the primary contraceptive method (42\%) among Muslims in Turkey ${ }^{16}$. A survey done in Bangladesh in 1986 also reported similar findings and attributed it to the religion ${ }^{14}$. In contrary to these, Ullah and the group in Bangladesh found that non-Muslim women were significantly less likely to use modern contraceptives compared to Muslim women ${ }^{17}$.

Though level of education was not significantly associated with the choice of method in the present study, a study conducted in Sri Lanka in 1987 had reported that the use of traditional methods was associated with lower level of education ${ }^{18}$. Findings from studies in other countries are inconsistent in this regard. In Bangladesh ${ }^{19}$ and in Australia ${ }^{20}$ educated women had chosen traditional methods while Turkish Demographic Health Surveys found that women with higher education choose modern methods ${ }^{21}$.

We found that living in an extended family was related to the choice of traditional methods $(p=0.001)$ may be due to influence by mothers-in-law and parents who may be having myths on modern methods. Turkish surveys also found that choosing traditional methods was associated with living in overcrowded households ${ }^{21}$.

Family income was not associated with choice of method in our study. This may be due to less variability in family income among study population in rural areas. Bangladesh found that women from higher socioeconomic backgrounds tend to choose traditional methods ${ }^{14,17,19}$. In contrast, Turkish women with better socioeconomic status chose modern methods ${ }^{21}$.

The reproductive health related factors associated with choice of traditional methods were youngest child's age being over six years $(p=0.012)$.
Women with the age of youngest child being over 6 years or more is considered as a proxy indicator for completion of family, this indicates that majority who had completed family use traditional methods and is at risk of ending up with unwanted pregnancies.

In our study, not having received detailed information regarding modern family planning was associated with use of traditional methods $(p=0.011)$. This highlights the importance of provision of adequate information on modern methods to promote its use among clients. This finding was supported by the review of research on choice of family planning methods which reported that use of hormonal methods were limited by lack of provision of information on them ${ }^{15}$. The fact that even among the traditional users a majority $(63.1 \%)$ indicated that they had received detailed information regarding modern family planning methods though they have not adopted a modern method, highlights the issue that providing information on the method alone is insufficient to promote the use of modern methods. Distance from field clinic being $>1 \mathrm{~km}(p=0.002)$ and not having ever utilized clinic services $(\mathrm{p}<0.001)$ being associated with choice of traditional methods indicate poor accessibility to services. A study in Ethiopia also found that poor accessibility to be associated with increased use of traditional methods ${ }^{22}$. Furthermore, review of research on choice of family planning found that the use of hormonal methods was limited by obstacles to access ${ }^{15}$. Not being visited at homes by PHM was significantly associated with traditional method use in our study $(p<0.001)$. Exploring the service related factors further, we found that negative opinion about PHM was associated with choice of traditional methods $(p<0.001)$. Furthermore, having negative opinion on family planning clinic services was also found to be related to the choice of traditional methods $(p<0.001)$. These findings are supported by the study done in Bangladesh which showed that the family planning services have very strong and positive influence on choice of contraceptives ${ }^{14}$. This highlights the importance of opinion of clients on the service provider and also the service centre in promoting services.

Having a poor overall knowledge on family planning methods was associated with the choice of traditional methods $(p=0.015)$ in our study. This finding is supported by the review report of qualitative research on choice of family planning methods which highlighted that the use of hormonal methods was limited by lack of knowledge $\mathrm{e}^{15}$. However, the study in Bangladesh found no association between knowledge about contraceptive methods and choice of a method ${ }^{14}$.

\section{Conclusions and recommendations}

Choice of traditional methods was associated with personal factors as well as service gaps which 
could be easily corrected. The interventions to promote modern family planning need to specifically target women who are Muslims and who are older. PHMM should be requested to maintain a close relationship with traditional family planning users and environment at family planning clinics should be made user friendly for all types of users, in order to promote modern methods. More educational programmes should be conducted targeting traditional family planning method users giving them specific technical knowledge related to practice of modern methods.

\section{References}

1. World Health Organization. Unsafe abortion, Global and regional estimates of the incidence of unsafe abortions and associated motility. Geneva: World Health Organization, 2003.

2. Eggleston E. Determinants of unintended pregnancy among women in Ecuador. International Family Planning Perspectives 1999; 25(1).

3. Vyas JN, Ahuja N. Textbook of Postgraduate Psychiatry. 2nd ed. New Delhi: Jaypee Brothers Medical Publishers Ltd., 1999.

4. Kilegman RM, Behrman RE, Jenson BH, Stanton BF. Nelson Textbook of Paediatrics.18th ed. New Delhi: Reed Elsevier India, 2008.

5. Ministry of Health. Annual Health Bulletin 2003. Ministry of Health, 2006.

6. Department of Census and Statistics and Ministry of Health. Sri Lanka Demographic and Health Survey 2006-2007. Department of Census and Statistics and Ministry of Health. 2009.

7. Family Health Bureau, 2009. Family Health Bureau website. [Online] (Updated 24 Nov 2009. Available at: http:// www.familyhealth.gov.lk/home.php [accessed June 2010].

8. Singh $S$, Wulf $\mathrm{D}$, Jones $\mathrm{H}$. Health professionals' perceptions about induced abortion in south central and southeast Asia. International Family Planning Perspectives 1997; 23(2).

9. World Health Organization. Health Situation in the SouthEast Asia Region 2001-2007. India: World Health Organization Regional Publication. 2009.

10. Ministry of Health and Family Health Bureau. Overview of maternal mortality in Sri Lanka 2001 - 2005. Sri Lanka: Ministry of Health, 2008.
11. Ministry of Health and Family Health Bureau, Annual Report on Family Health, Sri Lanka. Sri Lanka: Ministry of health, 2009.

12. De Silva WI. The silent cry: socio-cultural and political factors influencing induced abortion in Sri Lanka. Paper presented at the Seminar on Socio-Cultural and Political Aspects of Abortion from an Anthropological Perspective. Trivandrum, India, 25-28 March 1996.

13. Lawanga SK, Lemeshow S. Sample Size Determination in Health Studies. A Practical Manual. Geneva: World Health Organization, 1991.

14. Kabir M, Uddin MM, Chowdhury SR, Ahmed T. Characteristics of users of traditional contraceptive methods in Bangladesh. Journal of Biological Science 1986; 18(1): 23-33.

15. Williamson LM, Parkes A, Wight D, Petticrew M, Hart GJ. 2009. Limits to modern contraceptive use among young women in developing countries: a systematic review of qualitative research. [Online] (Updated 19 Feb. 2009) Available from http:/ / www.reproductive-health-journal .com/content 6/1/3 [Accessed June 2010].

16. Rogow $D$, Horowitz S. Withdrawal: a review of the literature and an agenda for research. Studies in Family Planning 1995; 26(3): 140-53.

17. Ullah MS, Chakraborty N. The use of modern and traditional methods of fertility control in Bangladesh: a multivariate analysis. Contraception 1994; 50(4): 363-72.

18. Cadwell JC, Gaminiratne K, Cadwell P, De Silva S, Cadwell B, Weeraratna N, Silva P. The role of traditional methods of fertility control in Sri Lanka. Studies in Family Planning 1987; 18(1): 1-21.

19. Kamal N, Saha UR, Ali Khan M, Bairagi R. Use of periodic abstinence in Bangladesh: do they really understand? Journal of Biosocial Science 2007; 39(1): 27-40.

20. Liskin LS. Periodic abstinence: how well do new approaches work? Population Report 1981; 1: 33-4.

21. Cindoglu D, Sirkeci I, Sirkeci RF. Determinants of choosing withdrawal over modern contraceptive methods in Turkey. The European Journal of Contraception and Reproductive Healthcare 2008; 13(4): 412-21.

22. Weldegerima B, Denekew A. Women's knowledge, preferences, and practices of modern contraceptive methods in Woreta, Ethiopia. Research in Social and Administrative Pharmacy 2008; 4(3): 302-7. 